I SIMPLE METHOD OF FINDING AN EASILY ACCESSIBLE PORTION OF THE LA'TERAL SINUS.*

* Read before the Wayne County (Detroit) Medical Society, $M: 7,1900$.

EMIL AMBERG, M.D. DETROIT, MICII.

lour right and four left temporal bones picked out at random, show that an easily accessible portion of the lateral sinus ean be found when we open that part of the mastoid process which is located (Fig. 1) in the direction of the line

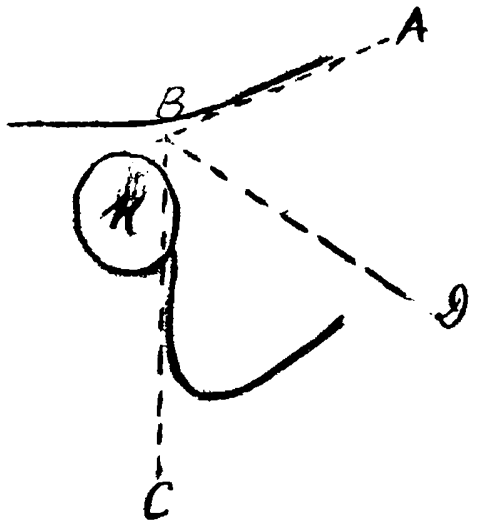

I'ig. 1.-M., Meatus externus. A. B., Linea temporalis. 13. C. Anterior mastoid line. B. D., Blsecting line of angle A. B. C. and directing line for lateral sinus.

which divides into two halves the angle formed by the linea temporalis and the anterior border of the mastoid process (an angle of about 115 degrees). This topographic consideration is important from a clinical point of view.

\section{CERTAIN MOTILE ORGANISMS IN THE BLOOD PLASMA IN DENGUE. CONRAD REICHE.}

Sergeant, IIospital Corps, U. S. Army CEBU, P. I.

While in charge of the laboratory of the military hospital in Cebu, P. I. (Captain Kulp) it was my duty to examine the blood of all malarial and dengue patients. An epidemic of the latter disease occurred during December, 1905, and lasted about six weeks. No malarial parasites were found, but I observed in nearly every case very active, small (about 2 micron), round translucent bodies, with clearly defined edges, very motile, and easily visible with a $1 / 6$ objective, but better with $1 / 12$ oil immersion lens. They were seldom or never found in the erythrocytes, but often on them, as well as free in the plasma. They appeared about the second day of the fever, and could never be found after the temperature became permanently normal or after the administration of quinin. They sometimes remained active for as long a period as an hour and three-quarters. Unfortunately, the epidemic ceased sud(lenly and the contemplated staining and mosquito experiments had to be abandoned.

\section{New Instruments}

\section{SE' OF 'THREE NEW INSTRUMENTS FOR THE TREATMENT OF CHRONIC ENDO- TRACHELITIS. \\ DANIEL H. CRAIG, M.D. BOSTON.}

The length of the three instruments is equal, and is $22 \mathrm{~cm}$. This length was chosen as the shortest which would enable the gynecologist to satisfactorily accomplish the treatment without allowing his hands to come in contact with the patient.
This secmed to me important because this method being designed for use at the office or out-patient clinic the thorough sterilization of the hands consumed too much time. With this length of instrument ordinary manual skill and dexterity render such sterilization entirely unnecessary.

The cervical forceps (Fig. 1) was designed to grasp the anterior aspect of the portio vaginalis as near as possible to, but not into, the external os. The tissues are here very often so soft as to tear when so grasped by the ordinary tenaculum or tenaculum forceps under the strain to which this grasp is to be subjected. The ordinary grasp with one blade within and the other without the cervical canal will later be seen to be obviously impossible in the use of either the dilator or the eurette. The two pairs of opposed teeth give a grip which has never lacerated. The curve on the flat facilitates the combined use of the forceps and dilator with one hand.

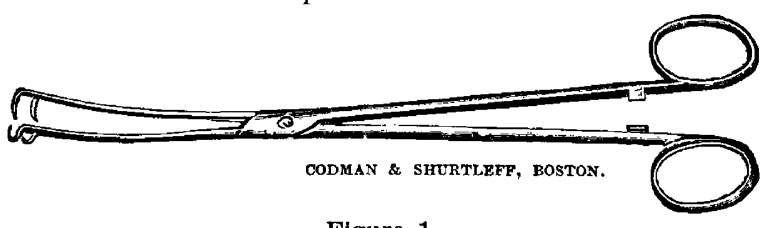

Figure 1.

The external os dilator was suggested by the conical calibrator used in dilating the external urinary meatus preparatory to cystoscopic work. Each of its dimensions is definite and has its raison d'être. It is of rigid steel throughout. The diameter of its tip is $2 \mathrm{~mm}$., which is as small as it could be made without actually giving it an angular point (Fig. 2). The length of the cone from tip to shoulder is $2 \mathrm{~cm}$. This length was chosen beeause being $0.5 \mathrm{~cm}$. less than the ordinary depth of the cervical canal it would even permit of some eversion, due to laceration, without the tip of the cone impinging on or going through the contracted internal os. A cervix in which there is more than $0.5 \mathrm{~cm}$. foreshortening, owing to laceration and eversion, is so patulous as not to require the use of any dilator. The narrow parallel surface just below the shoulder facilitates the retention of the dilator within the ex-

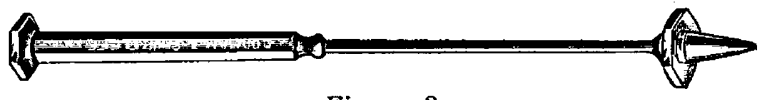

Figure 2.

ternal os long enough to produce sufficient relaxation without maintaining so forcible a degree of pressure as to be constantly disagreeable to the patient. The shoulder is, of course, self-explanatory. The flattened base of the handle facilitates the maintenance of a steady unirritating pressure. The perimeters of the shoulders are made hexagonal to prevent rolling and so coming in contact with unsterilized material.

The only features about the curette which need attention are the shape and width of its cutting blade. It is sharp, the edge being obtained by beveling from above downward and inward, making the blade cut as the curette is withdrawn. The blade and its fenestrum are triangular, presenting a base of $6 \mathrm{~mm}$. and relatively sharp angles. The base is just twice

Figure 3.

the diameter of the normal internal os as stated by Deaver (Fig. 3). This excess width serves to render it impossible to introduce the curette past the internal os, unless it be dilated, which in itself constitutes a contraindication to the use of this curette, without the employment of sufficient force to lacerate the tissues. The sharp angles serve on the rotation of the curette, to remove the pathologic tissues too near to the internal os to be readily reached in the ordinary traction of the curette, and are especially useful in those cases in which a sharp angle exists just below the internal os due to pressure atrophy with excavation or internal laceration of the cervix. Three furrows on the appropriate surface of the hexagonal handle indicate the direction of the cutting blade. The curette is of rigid steel throughout, no necessity for flexibility having been encountered. 